\title{
Responding to health and social needs of aging Latinos in new-growth communities: a qualitative study
}

\author{
Kim Larson ${ }^{1 *} \mathbb{D}$, Holly F. Mathews ${ }^{2}$ Essie Torres ${ }^{3}$ and C. Suzanne Lea ${ }^{4}$
}

\begin{abstract}
Background: The development of new-growth communities of Latino immigrants in southern states has challenged the traditional health and social service infrastructure. An interprofessional team of service providers, Latino leaders, and university faculty partnered to establish linkages with the Latino community and providers serving aging adults and to explore the health and social needs of aging Latinos residing in a rural region.

Methods: A qualitative descriptive study was conducted through a community-university partnership, the Aging Latino Research Team (ALRT). Data were generated from nine focus groups and 15 key informant interviews with Latino and non-Latino community members and service providers in rural, eastern North Carolina (ENC).

Results: Thematic analysis was used to identify common patterns and form recommendations for future research and programs. Themes common to Latino participants were: "We are put off to one side"; "If I can't work, I can't survive"; and "Without documents, you are no one." Themes common to non-Latino participants were: "Older Latinos are not well served"; "Older Latinos are invisible"; "Older Latinos are undocumented and afraid"; and "Older Latinos are wandering the highway".

Conclusion: A major finding of this research was the extent to which discrepancies in perceptions between Latino participants and non-Latino participants exist. These discrepancies revealed ethnic stereotyping and cultural insensitivity as major barriers in access to care.
\end{abstract}

Keywords: Latinos, New-growth community, Interprofessional, qualitative description

\section{Background}

The Latino population in the United States of America (US) is increasing in size, visibility, and diversity. Projections are that Latinos aged 65 and older will increase from the current $8 \%$ of the US population to $22 \%$ by $2060[1,2]$. Data support that aging Latinos are more likely to have limited formal education, lower income, and poorer health outcomes than the general population $[3,4]$. Adversity over the life course, punctuated by low incomes and few assets, results in economic insecurity in old age [5].

Historically, Latino populations have been concentrated in California, Texas, Florida, and New York [6].

\footnotetext{
*Correspondence: larsonk@ecu.edu

${ }^{1}$ College of Nursing, East Carolina University, 3135 Health Science Building,

Greenville, NC 27858, USA

Full list of author information is available at the end of the article
}

Latino resettlement across the US has generated newgrowth communities especially in the Southeast, Midwest, and Northeast [7-9]. New-growth communities are those with an emergent and growing concentration of Latinos in areas with no previously established population [7]. Several studies have reported on the health status of Latinos in new-growth communities in the Midwest and Northeast, but these studies have focused on young Latino men or urban Latino residents.

The Southeastern region leads the US in Latino population growth $[10,11]$ and North Carolina's (NC) Latino population increased by $111 \%$ between 2000 and 2010 [12]. In 2014, an estimated 890,000 Latinos resided in $\mathrm{NC}$, of which $11 \%(97,000)$ were age 50 years and older [13] compared to $9 \%$ nationally [14]. No studies were found that focused on the health and social service needs of aging Latinos in new-growth communities in 
the rural southeastern US, such as those found in NC. The purpose of this study was two-fold: to establish linkages with the Latino community and providers serving aging adults and to describe the health and social needs of aging Latinos in rural eastern $\mathrm{NC}$ (ENC). For this study, the aging Latino population was defined as age 50 and older, specifically immigrants from Mexico and Central America, who have chosen to reside in NC. The majority of services for seniors in North Carolina begin at age 55; using age 50 captures the number of Latinos approaching eligibility for purposes of strategic planning.

\section{Contextual significance}

In NC, 33.6\% of Latinos live below the federal poverty level compared to $17.2 \%$ in the general population, and are three times more likely to be uninsured than nonHispanic Whites [15]. Although the leading causes of death among Latinos in $\mathrm{NC}$ are similar to the general population, such as cancer, heart disease and stroke, the prevalence of risk factors for these chronic conditions is disproportionately higher among Latinos [16]. A recent study on immigration policies and the Latino population in NC has identified infrastructure weaknesses, such as lack of qualified interpreters, public transportation in rural areas, and primary care providers [9].

Three studies evaluated health and social service needs of Latinos in new-growth communities in the Midwest and Northeast. In the Midwest, Lanesskog et al. [17] conducted interviews with 25 professionals predominately from the education sector, with equal numbers of non-Latino and Latino participants. The four factors that assisted service delivery to Latinos were language competence, cultural knowledge in multiple contexts, empathy toward clients, and the will to act [17]. A study in the Northeast used a community-based participatory research approach to assess the health needs of immigrant Latino men [18]. Data were generated from four focus groups with Latino men and interviews with 10 health and social service staff. The three themes reported were social isolation, staying healthy, and accessing the health care system [18]. The third study was a needs assessment conducted in Baltimore, Maryland, and among the five focus groups only one included aging Latino women [19]. The top health concerns of this group were "bone-related disease," hypertension and high cholesterol, stress (nervios), respiratory problems, diabetes, influenza, and AIDS. Barriers reported by all study participants were linguistic, cultural, financial, legal, and logistical (transportation and communication).

We framed our study on various theoretical views and findings that emphasize interpersonal linkages and cultural attributes salient to health care utilization and access barriers among aging Latinos [20, 21]. This modified framework featured macro upstream factors including socio-demographic characteristics, social determinants of health, and health and social service outcomes.

\section{Methods}

This qualitative descriptive study was conducted by the Aging Latino Research Team (ALRT), a communityuniversity partnership between the Eastern Carolina Council Area Agency on Aging (AAA) and East Carolina University (Greenville, North Carolina). Key administrators from the AAA, a Latino leader from the target region, and faculty from Anthropology, Health Education and Promotion, Nursing, Public Health, and Sociology comprised this interprofessional, bilingual research team. The ALRT members designed structured interview guides using language and cultural concepts relevant for the Latino population. Six university students in nursing, public health, and anthropology assisted the research team. This study focused on three target counties, Duplin, Greene, and Wayne, in ENC, all of which have Latino populations $(11 \%-22 \%)$, exceeding the statewide average (9\%) [22]. The university institutional review board approved the study. A waiver of signed informed consent was granted and verbal consent was obtained from all participants.

\section{Sample and setting}

Service providers from eight ENC counties were recruited by the key administrator from the Eastern Carolina Council AAA. Focus groups were planned in conjunction with a scheduled regional meeting and conducted after the meeting for the convenience of participants. Twenty-six individuals participated in one of four focus groups held concurrently at the AAA regional office. These participants included staff from AAA, senior centers, social services and health departments, Spanish interpreters and an immigration attorney. The majority (92.3\%) of provider focus group participants were white females.

Participants for Latino focus groups were recruited through local churches and community leaders in the three target counties. Thirty-nine Latino community members aged 50 and older participated in five focus groups. Among the five Latino focus groups, both men $(28.2 \%)$ and women $(71.7 \%)$ were represented. The majority of participants were from Mexico and fewer were from Honduras, Guatemala, and El Salvador. The focus group demographics are presented in Table 1.

Fifteen key informants from the three target counties were identified through snowball sampling. Key informants were known to focus group or research team members as having had long-term contact with Latinos in their communities. These included male (40\%) and 
Table 1 Focus Group Demographics

\begin{tabular}{|c|c|c|c|c|c|c|c|c|c|}
\hline \multirow{3}{*}{$\begin{array}{l}\text { Focus } \\
\text { Groups }\end{array}$} & \multicolumn{4}{|c|}{ Provider Focus Groups (PFG) N = 4} & \multicolumn{5}{|c|}{ Latino Focus Groups (LFG) N = 5} \\
\hline & PFG1 & PFG2 & PFG3 & PFG4 & LFG1 & LFG2 & LFG3 & LFG4 & LFG5 \\
\hline & $n=6$ & $n=6$ & $n=7$ & $n=7$ & $n=4$ & $n=10$ & $n=3$ & $n=8$ & $n=14$ \\
\hline \multicolumn{10}{|l|}{ Sex } \\
\hline Female & 4 & 6 & 7 & 7 & 3 & 7 & 3 & 3 & 12 \\
\hline Male & 2 & 0 & 0 & 0 & 1 & 3 & 0 & 5 & 2 \\
\hline \multicolumn{10}{|c|}{ Race/Ethnic Background } \\
\hline White & 4 & 4 & 5 & 4 & 0 & 0 & 0 & 0 & 0 \\
\hline Black & 1 & 1 & 1 & 3 & 0 & 0 & 0 & 0 & 0 \\
\hline Latino & 1 & 1 & 1 & 0 & 4 & 10 & 3 & 8 & 14 \\
\hline \multicolumn{10}{|c|}{ Target Counties Represented } \\
\hline Duplin & $x$ & & & $x$ & & $x$ & & & \\
\hline Greene & & $x$ & $x$ & $x$ & & & & & $x$ \\
\hline Wayne & $x$ & & $x$ & $x$ & $x$ & & $x$ & $x$ & \\
\hline Other & $x$ & $x$ & $x$ & $x$ & & & & & \\
\hline
\end{tabular}

female (60\%), Latino (53\%) and non-Latino (47\%) service providers, business professionals, community advocates, faith-based community members, and Latino leaders.

\section{Data collection}

Data were collected between October 2015 and June 2016. The three data sets were: a) service provider focus groups, b) Latino community member focus groups, and c) key informants (Latino and non-Latino). All interviews and focus groups were audio-taped, followed a structured interview guide (available on-line as supplemental material), lasted approximately 30-90 min, and were transcribed within several days after the meeting date. Research team members moderated and comoderated all focus groups and conducted all key informant interviews. Interviews took place at convenient community locations and in the preferred language of participants, either English or Spanish. Spanish transcripts were translated by a native speaker into English. Participants received either a gift card or padfolio for their contribution to the study.

\section{Data management and analysis}

Focus group and key informant transcripts were read independently by all research team members. The research team met monthly to discuss coding strategies and come to consensus on findings. A matrix was created of the focus group transcripts organized by interview question to identify key concepts and facilitate between case and within case comparisons. The ALRT members had on-going discussions to determine commonalities and differences. A constant comparison approach was used to identify patterns in the data and discover relationships between ideas or concepts [23].
Transcripts from key informant interviews were analyzed in two ways. First, a content analysis [24] was performed to tabulate answers to the interview questions and compare these across participants looking for common patterns. Next, transcripts were analyzed following a Grounded Theory framework to identify broader themes emblematic of attitudes shared by a group $[25,26]$. Triangulation between the three data sets was used to discover commonalities in health problems, barriers to care, and health perceptions until data saturation was achieved.

\section{Results}

Major health issues facing aging Latinos in order of frequency are described in Table 2. Chronic diseases, particularly diabetes, heart disease and hypertension, were reported as the top health concerns of aging Latinos by all focus groups. The acute health problems reported were heat stress and work-related injuries, broken bones, and respiratory infections. Mental health issues reported included dementia, Alzheimer's disease, depression, stress, and insomnia. Additional complaints were obesity, poor nutrition, and problems with hearing, vision, and dental care. Two culture-bound syndromes reported were susto (fright) and nervios (nerves). Only Latino focus group participants emphasized musculoskeletal problems, such as arthritis.

Perceived barriers to health and social service programs at the individual and systems levels are displayed in Table 3 . We note that some barriers could be relevant at both levels.

\section{Individual barriers}

Inability to speak English and low levels of formal education were major barriers for many aging Latinos. Low 
Table 2 Major health issues for aging Latinos

\begin{tabular}{|c|}
\hline Chronic Disease and Chronic Disease Management Issues: \\
\hline 1. Diabetes \\
\hline 2. Heart Disease \\
\hline 3. Hypertension \\
\hline 4. High cholesterol \\
\hline 5. Arthritis \\
\hline 6. Rheumatism \\
\hline 7. Asthma \\
\hline 8. Bronchitis \\
\hline 9. Cancer \\
\hline Problems Secondary to Poor Diabetes Self-Management: \\
\hline 1. Vision problems \\
\hline 2. Limb/ft problems \\
\hline 3. Kidney disease \\
\hline 4. Liver disease \\
\hline Mental Health Issues: \\
\hline 1. Dementia \\
\hline 2. Alzheimer's disease \\
\hline 3. Depression \\
\hline 4. Stress \\
\hline 5. Insomnia \\
\hline Acute Health Issues: \\
\hline 1. Heat Stress \\
\hline 2. Work-related injuries; broken bones \\
\hline 3. Sexually transmitted infections \\
\hline 4. Respiratory infections \\
\hline Other Health Issues: \\
\hline 1. Alcoholism (especially among men) \\
\hline 2. Obesity and poor nutrition \\
\hline 3. Bone/joint problems \\
\hline 4. Dental problems \\
\hline 5. Hearing issues \\
\hline Culture-bound Syndromes: susto and nervios \\
\hline
\end{tabular}

wages and lack of health insurance were related to the types of employment available to immigrant workers. Aging Latinos without legal status lacked access to some services, while others were unsure about eligibility requirements. Lack of family support and social isolation in rural ENC also impacted health outcomes dramatically.

\section{System barriers}

Most health and human services agencies in the target counties lacked Spanish-speaking interpreters often due to insufficient funding. One service provider focus group reported that a social service agency serving older adults
Table 3 Perceived barriers to access health care for aging Latinos

Individual level:

- Inability to speak English

- Low educational levels

- Lack of health literacy

- Lack of private transportation

- Inability to obtain a driver's license

- Low incomes

- Lack of health insurance

- Undocumented status and inability to qualify for services

- Lack of knowledge about eligibility requirements for different services

- Lack of telephones making patient follow-up difficult

- Lack of family support

Systems level:

- Limited hours of operation at health facilities

- Shortage of primary care providers

- Long delays in obtaining appointments

- Lack of Spanish-speaking personnel in health agencies

- Discrimination due to lack of cultural sensitivity

- Lack of public transportation in rural areas

- Undocumented status and inability to qualify for services

- Lack of information in Spanish on services available to aging adults

- Expensive fees for service

- Agencies with limited budgets must target state and federal priorities

- Ongoing budget cuts limit hiring of bilingual staff or translation services

- Competition at the local level between agencies for resources

- Lack of community partnerships to assist Latinos

had recently adopted an "English-only" workplace policy. Bilingual interpreters were often shared by multiple agencies and Latino advocacy groups in the target counties were absent. Service providers reported lack of funding and interagency competition for limited resources. Further noted was a lack of community partnerships or efforts to collaborate to find mutual solutions to service needs and programmatic gaps.

Aging Latinos experienced discrimination in the health care system from both providers and staff members, even when they themselves were Latino. For example, Latinos waited longer than other clients to be seen by providers. Latinos also perceived that they were treated rudely, looked down upon for lack of formal education and undocumented immigration status, and were rushed through their appointments. Public transportation in rural areas was either absent or not available to undocumented residents, who also had difficulty obtaining an official driver's license due to state policies. 
A shortage of primary care providers contributed to the long delays in obtaining appointments. Some agencies also had limited hours of operation, and fees for service were sometimes costly, further limiting accessibility. Latino focus group participants reported the use of various strategies to manage costs such as not purchasing full supplies of medicines, not taking the full amount prescribed, borrowing medicines from other people, using home remedies and consulting with alternative practitioners such as herbalists and curanderos (natural healers).

The eligibility criteria for some social services were unclear for aging Latinos. Differences in eligibility requirements were noted by county and funding source. For example, eligibility for services offered by AAA, such as medication assistance, in-home care, and home meal deliveries, varied between counties. Yet, even when eligible, some aging Latinos reported being turned away due to either lack of clarity about eligibility criteria by service providers or absence of interpreters. Aging Latinos were also afraid to seek out services due to fear of deportation as a result of local law enforcement collaborating with the federal Immigration and Customs Enforcement agency.

Thematic analysis revealed key differences between Latino and non-Latino participants. These are discussed below and labeled with a quotation that encapsulates the meaning behind each theme. Three themes characterized the perceptions of Latino participants. The first theme was "We are put off to the side." Latino participants felt they were discriminated against by health and service providers because of their ethnicity and lack of English language skills. Participants reported feeling as if their needs were put aside. For example, participants reported waiting for services only to find out no help was available. They perceived that they did not have a voice. As one person articulated, "Even the receptionist at the window will not attend to us the same as they attend to others."

The second theme was "If I can't work, I can't survive." Participants emphasized that aging Latinos can never retire. If they become sick or disabled, aging Latinos have no government support. Since the majority work at hard physical labor, ill health, particularly diseases that impact work ability, are a major problem. For example, one person reported having trouble working and managing his diabetes, while another recounted how arthritis and knee pain caused him to lose his job and become homeless.

The third theme was "Without documents, you are no one." Participants pointed out that Latinos arrive from many different countries; some on temporary visas, some have permanent residency, but others are undocumented residents. The undocumented residents are often discriminated against even within the Latino community.

Four themes characterized the perceptions of nonLatino participants. The first theme was "Older Latinos are not served well." Non-Latino participants agreed that public agencies in these counties did not serve Latinos well due to the lack of Spanish language and cultural skills training among staff. When staff members treat Latinos poorly, they do not return. Providers were aware and recognized this issue although providers also noted it was sometimes due to situational factors not intent. As one person articulated, "When physicians and nurses are driven by the need to see a lot of people in a short time and it takes more than twice as long to evaluate a Latino patient, they cut corners [when interacting with the Latino patient]."

The second theme was "Older Latinos are invisible." Non-Latino participants discussed how aging Latinos live with their families and are hidden from public view. As one person said, "You do not see them on the streets very often or out and about." The assumption among non-Latino participants was this invisibility is a positive sign because the Latino culture is family-oriented and families willingly provide care for Latino elders.

The third theme was "Older Latinos are undocumented and afraid." Non-Latino participants assumed that aging Latinos are undocumented and are afraid to access services because they fear deportation. Further, they saw aging Latinos as unwilling to seek out information on services or attend community events because of these fears. For these same reasons they are unable to drive or get to services. As one person replied, “... changes need to come from above; the political system, before we can do anything."

The fourth theme was "Older Latinos are wandering the highway." Non-Latino participants observed occurrences of aging Latinos wandering in the community, lost and confused. There are few mental health facilities for aging Latinos making referrals and care challenging. One service provider was informed of a working Latino family who left their aging relative alone during day and he often went missing.

\section{Discussion}

The key findings from our study of aging Latinos in a new-growth community support both those reported for new migrant populations and long-established Latino communities. Similar to other recent migrant populations engaged primarily in farm work, our participants reported a range of work-related musculoskeletal problems and occupational-related injuries. Yet providers and Latinos also listed chronic diseases similar to those experienced by longer-established communities [7, 19, 27]. Unique to our sample was the identification of dementia and related disorders by service providers.

The focus groups and key informants identified several chronic conditions perceived to be increasing among aging Latinos that are similar to those found in other 
studies [19, 28]. These conditions include diabetes, heart disease, hypertension and high cholesterol. Participants also placed emphasis on arthritis and other musculoskeletal problems which have not been as widely reported in other studies. Cheriel et al. [29] note that the burden of arthritis in the US is minimized by providers due to underutilization of best practice interventions, lack of access to care, and cultural and language barriers.

Latino participants in this study, like those in other studies of new growth communities [19, 30] also listed mental health concerns including depression, stress and anxiety as problems they experienced but for which they had not sought treatment. Additionally, two culturebound syndromes of susto (fright) and nervios (physical and/or mental unrest) were reported. Both present with symptoms of distress; however, nervios is related more with continual stresses, while susto has been related to a single stressful event [31]. Baer et al. [31] reported that nervios was not perceived as a mental illness by a sample of Mexican-American and Guatemalan farmworkers. In our study, participants referred to susto and nervios in response to the anxieties and stresses experienced with immigration and fears of deportation. These findings confirm results from the National Latino and Asian American Study by Alegria et al. [32], which found that US born Latinos have higher rates of mental disorders, particularly anxiety, depression and substance abuse, than do more recent immigrants. A review of service use found that Latinos underutilize mental health services and rely on primary care providers making them less likely to receive congruent care [33]. It would seem of great importance for clinicians working with these populations to understand how the terms nervios and susto (and possibly other culture-bound syndromes) are used, and further investigate their relationship to stress, depression, physiological symptoms, and other mental health conditions.

A unique finding of this study was the discrepancy found in perceptions between Latino and non-Latino participants regarding access to care, familism, and mental health. Latino participants viewed unnecessary long clinic waits, poor customer service, and lack of concern by providers as discrimination. This finding aligns with research showing that $30 \%$ of Latinos nationwide believe that racism is a major problem in health care and that $58 \%$ are concerned about being treated unfairly due to race/ethnicity when seeking care [34].

In contrast, service providers believed Latino clients were not treated well due to situational factors, such as not taking time to determine eligibility, lack of interpreters, and lack of cultural competence. Addressing this discrepancy is as critical as eliminating access barriers because when Latinos are treated poorly, they tend to not return for healthcare. This leads to missed appointments, lack of trust, lack of information, and underutilization of preventive health and social services that may result in adverse outcomes [28].

Familism was also perceived differently by these two groups. Latino participants expressed the need to work and not depend on family members for financial and caregiving support. Service providers assumed that Latino families did not want to use government services and that they preferred to care for their elders. There is limited research on family support in immigrant communities; however, two studies suggest that Chinese and Korean elders receive less family support in the US and perceive they must depend more upon themselves $[35,36]$. The implication of this assumption by service providers is that Latino families are doing an adequate job and do not need or want help for aging family members. Although some aging Latinos are cared for by family members, providers should not assume relatives are able to do so. One solution would be to assess aging Latinos for independence in activities of daily living and refer families to appropriate resources.

While Latino participants did not verbalize dementia as a major health condition, the service providers noted incidents of aging Latinos lost and confused with potential signs of dementia. These three target counties lack dementia care facilities or home respite care. Therefore, working Latino families are challenged to provide care for affected relatives. Our findings are consistent with those of Gonzalez, Haan and Hinton [37] who documented an overall dementia prevalence of $31 \%$ among their sample of Latinos in California age 80 and over. These investigators also reported $43 \%$ of dementia was directly attributable to type 2 diabetes mellitus, stroke or a combination of the two. These findings suggest that the high prevalence of diabetes among Latinos in ENC may lead to increasing prevalence of dementia as this population ages. An effective public health approach to address this looming problem is to focus on primary and secondary prevention of diabetes among younger Latinos.

Our study also confirms common access barriers in other studies that focus on Latino new-growth communities in general. These barriers include language $[19,30$, $38,39]$, cultural insensitivity $[18,19,39]$, lack of interpreters [19, 39], transportation [19, 38, 39], immigration issues [19, 38], lack of insurance [19, 28, 38, 39], and cost of care [18, 19, 30, 39]. An important finding unique to our study is the legitimate fear that aging Latinos in new-growth communities in ENC have of deportation due to racial profiling and harassment. Undocumented status in the US offers no form of security, provides limited civil and labor rights, and creates a significant barrier for immigrant integration into communities [40]. Increasingly, certain laws have 
made it easier to shift from documented to undocumented status (i.e. H-2a temporary agricultural workers program) but not vice versa, placing many immigrants in legal limbo for indefinite periods of time [41]. This shift has led to more extensive law enforcement strategies, which heightens the risk for deportation, immigration raids, and civil rights violations among undocumented community members [40]. In ENC, these enforcement strategies have been reported to include a variety of public spaces, such as churches, community clinics, public bus stops, and traffic stops. Therefore, these experiences have negative consequences for daily lives of Latino community members in new-growth communities, and are a critical barrier in access and use of health and social services. It is important to note that legal status intensifies the effects of disadvantages, and has intergenerational impacts on communities [40], which can potentially further exacerbate existing health disparities. Future research needs to examine the intergenerational effect of legal status on health within a family and community context.

\section{Strengths and limitations}

The strengths of this study were the use of purposive sampling to recruit both service providers and Latino community members, which allowed for identification of overlapping perceptions from different viewpoints. The key informants represented a wide variety of community leaders. These samples also generated rich data from focus groups and key informants. One limitation was that the provider sample was predominantly white and female, reflecting provider demographics in the Eastern Carolina Council AAA. This racial and gender bias may impede a full understanding of Latino cultural issues. Still, respondents recognized this limitation in the data. The study was also limited by the current fears prevalent among undocumented Latinos, which restricted the collection of detailed demographic data on Latino focus group participants.

\section{Conclusions}

This is the first study to demonstrate discrepancies in perceptions among Latino and non-Latino participants, and the potential implications these attitudes can have on service delivery at various levels. These discrepancies may contribute to missed clinical and community-based opportunities to empower and intervene with families to thwart some of the potential intergenerational health effects of discrimination and lack of access to needed health and social services. This study also strongly suggests that service providers in new-growth, and largely rural, communities could benefit from cultural sensitivity training. Service providers with the Eastern Carolina Council AAA programs are incorporating the study's findings into their current strategic plans.

\section{Abbreviations}

AAA: Area agency on aging; ALRT: Aging Latino research team; ENC: Eastern North Carolina; LFG: Latino focus groups; PFG: Provider focus groups

\section{Acknowledgements}

We are grateful to the administrators with Eastern Carolina Council AAA for their partnership and assistance in the implementation of this study. In addition, we would like to thank the service providers and community members who participated.

Funding

This work was supported by an intramural grant from the East Carolina University Office of Research and Graduate Studies.

Availability of data and materials

Data are available from the corresponding author upon reasonable request.

Authors' contributions

$\mathrm{KL}, \mathrm{HM}, \mathrm{ET}$, and SL were responsible for obtaining funding, study plan, design, implementation, and analysis. All authors wrote the initial

manuscript, revised and approved the final manuscript.

Ethics approval and consent to participate

This study received institutional review board approval (ID: UMCIRB 15001260) from East Carolina University and voluntary verbal consent was given by all participants.

Consent for publication

Not applicable.

\section{Competing interests}

The authors declare that they have no competing interests.

\section{Publisher's Note}

Springer Nature remains neutral with regard to jurisdictional claims in published maps and institutional affiliations.

\section{Author details}

${ }^{1}$ College of Nursing, East Carolina University, 3135 Health Science Building, Greenville, NC 27858, USA. ²Department of Anthropology, East Carolina University, Greenville, NC 27858, USA. ${ }^{3}$ Department of Health Education and Promotion, East Carolina University, Greenville, NC 27858, USA. ${ }^{4}$ Department of Public Health, Brody School of Medicine, East Carolina University, Greenville, NC 27858, USA.

Received: 24 April 2017 Accepted: 15 August 2017

Published online: 25 August 2017

References

1. Riosmena F, Wong R, Palloni A. Migration selection, protection, and acculturation in health: a binational perspective on older adults. Demography. 2012;50:1039-64.

2. Mather M, Jacobsen LA, Pollard KM. Aging in the United States. Population bulletin 70.2. Washington: Population Reference Bureau; 2015. Retrieved on July 16, 2017 from http://www.prb.org/pdf16/aging-us-population-bulletin. pdf.

3. Gassoumis ZD, Wilber KH, Baker LA, Torres-Gil FM. Who are the Latino baby boomers? Demographic and economic characteristics of a hidden population. J of Aging and Social Policy. 2010;22:53-68.

4. Hummer RA, Benjamins MR, Rogers RG. Racial and ethnic disparities in health and mortality among the U.S. elderly population. In: Anderson NB, Bulato RA, Cohen B, editors. Critical perspectives on racial and ethnic differences in health in late life. Panel on race, ethnicity, and health in later life. Committee on population, division of behavioral and social sciences and education. Washington: The National Academies Press; 2004. p. 53-94.

5. Frytak JR, Harley $C R$, Finch MD. Socioeconomic status and health over the life course. In: Mortimer JT, Shanahan MJ, editors. Handbook of the life course. New York: Kluwer Academic/Plenum Publishers; 2003. p. 623-43.

6. Pew Research Center: Trends 2005. Hispanics: A People in Motion. Retrieved on October 16, 2016 from http://www.pewresearch.org/2005/01/20/trends2005/. 
7. Cunningham $\mathrm{P}$, Banker M, Artiga S, Tolbert J. Health coverage and access to care for Hispanics in "new growth communities" and "major Hispanic centers.". Washington, DC: Kaiser Commission on Medicaid and the Uninsured; 2006

8. Ennis SR, Rios-Vargas M, Albert NG. Census brief C2010BR-04. The Hispanic population. Washington: US Census Bureau; 2010. p. 2011.

9. Mann L, Siman FM, Downs M, Sun CJ, Urquieta de Hernandez B, Garcia M, et al. Reducing the impact of immigration enforcement policies to ensure the health of north Carolinians: statewide community-level recommendations. N C Med J. 2016;77(4):240-6.

10. Krogstad, JM. Key facts about how the U.S. Hispanic population is changing. Pew Research Center. Retrieved on August 20, 2017 from http:// wwwpewresearch.org/fact-tank/2016/09/08/key-facts-about-how-the-u-shispanic-population-is-changing/.

11. Stepler R, Lopez MH. U.S. Latino population growth and dispersion has slowed since onset of the great recession. Pew Research Center, Hispanic Trends. Retrieved on October 14, 2016 from http://wwwpewhispanic.org/ 2016/09/08/latino-population-growth-and-dispersion-has-slowed-sincethe-onset-of-the-great-recession/.

12. Tippett R. North Carolina's Hispanic Population, By State, County and City. Carolina Demography website. Retrieved on October 14, 2016 from https://demography.cpc.unc.edu/2014/10/07/north-carolinas-hispanicpopulation/.

13. Pew Research Center: Demographic profile of Hispanics in North Carolina, 2014. Retrieved on October 14, 2016 from http://www.pewhispanic.org/ states/state/nc.

14. American Association of Retired People Report on Age 50+ Population. 2014. Retrieved on July 17, 2017 from http://www.aarp.org/content/dam/ aarp/research/surveys_statistics/general/2014/Getting-to-Know-AmericansAge-50-Plus-Demographics-AARP-res-gen.pd.

15. North Carolina Department of Health and Human Services: North Carolina Resident Population health data by race and ethnicity. Division of Public Health, State Center for Health Statistics, November, 2015. Retrieved on July 7, 2016 from http://www.schs.state.nc.us/schs/pdf/ NCPopHealthDatabyRaceEthNov2015.pdf.

16. North Carolina Department of Health and Human Services: North Carolina Minority Health Facts: Hispanic/Latinos. Office of Minority Health and Health Disparities, State Center for Health Statistics, July, 2010. Retrieved on July 7, 2016 from http://www.schs.state.nc.us/schs/pdf/Hispanic_FS_WEB_080210. pdf.

17. Lanesskog D, Piedra LM, Maldonado S. Beyond bilingual and bicultural: serving Latinos in a new-growth community. Journal of Ethnic \& Cultural Diversity in Social Work. 2015;24:300-17.

18. Documet Pl, Kamouyerou A, Pesntes A, Macia L, Maldonado H, et al. Participatory assessment of the health of Latino immigrant men in a community with a growing Latino population. Journal of Immigrant Minority Health. 2015;17:239-47.

19. Martinez IL, Carter-Pokras O. Assessing health concerns and barriers in a heterogeneous Latino community. J Health Care Poor Underserved. 2006; 17:899-909.

20. Mendes de Leon CF, Glass TA. The role of social and personal resources in ethnic disparities in late-life health. In: Anderson NB, Bulatao RA, Cohen B, editors. Critical perspectives on racial and ethnic differences in health in late life. Panel on race, ethnicity and health in later life. Committee on population, division of behavioral and social sciences and education. Washington: The National Academies Press; 2004. p. 353-405.

21. Link BG, Phelan J. Social conditions as fundamental causes of disease. J Health Soc Behav. 1995;35(Extra Issue):80-94

22. Stepler R, Brown A. Statistical portrait of Hispanics in the United States. Pew research center. Hispanic Trends. Retrieved on February 7, 2017 from http:// www.pewhispanic.org/2016/04/19/statistical-portrait-of-Latinos-in-theunited-states/.

23. Krueger RA, Casey MA. Focus groups: a practical guide for applied research. 5th ed. Thousand Oaks: Sage Publications, Inc; 2015.

24. Neuendorf KA. The content analysis guidebook. Thousand Oaks: Sage; 2002.

25. Glaser BG, Strauss AL. The discovery of grounded theory: strategies for qualitative research. Aldine Transaction: New Brunswick \& London; 2009.

26. Strauss A, Corbin J. Basics of qualitative research: techniques and procedures for developing grounded theory. Thousand Oaks: Sage Publications, Inc; 1998
27. National Council of La Raza: An Inside Look at Chronic Disease and Health Care among Hispanics in the US, 2014. Retrieved on July 17, 2017 from http://www.lchc.org/wp-content/uploads/Chronic_Disease_Report_2014.pdf.

28. Keller SC, et al. Perceived discrimination and use of health care services in a North Carolina population of Latino immigrants. Hispanic Health Care International. 2010;8(1):4-13.

29. Cheriel C, et al. Arthritic pain among Latinos: results from a communitybased survey. Arthritis Care \& Research. 2009;61(11):1491-6.

30. Valenzuela JM, McDowell T, Cencula L, Hoyt L, Mitchell MJ. ¡Hazlo Bien! A participatory needs assessment and recommendations for health promotion in growing Latino communities. Health Promotion. 2013;27(5):339-46.

31. Baer RD, Weller SC, de Alba Garcia JG, Glazer M, Trotter R, Pachter L, Klein RE. A cross-cultural approach to the study of the folk illness nervios. Cult Med Psychiatry. 2003;27(3):315-37.

32. Alegria M, Mulvaney-Day N, Torres M, Polo A, Cao Z, Canino G. Prevalence of psychiatric disorders across Latino subgroups in the United States. Am J Public Health. 2007;97(1):68-75.

33. Cabassa $\sqcup$, Zayas LH, Hansen MC. Latino adults' access to mental health care: a review of epidemiological studies. Adm Policy Ment Health Ment Health Serv Res. 2006;33:316-30.

34. Institute of Medicine (US) Committee on Understanding and Eliminating Racial and Ethnic Disparities in Health Care; Smedley BD, Stith AY, Nelson $A R$, eds. Unequal treatment: confronting racial and ethnic disparities in health care. Washington: National Academies Press; 2003.

35. Wong ST, Yoo GJ, Stewart AL. The changing meaning of family support among older Chinese and Korean immigrants. J Gerontol Ser B Psychol Sci Soc Sci. 2006;61(1):S4-9.

36. Lan PC. Subcontracting filial piety: elder care in ethnic Chinese immigrant families in California. J Fam Issues. 2002;23(7):812-35.

37. González HM, Haan MN, Hinton L. Acculturation and the prevalence of depression in older Mexican Americans: baseline results of the Sacramento area Latino study on aging. J Am Geriatr Soc. 2001;49:948-53.

38. Garcés IC, Scarinci IC, Harrison L. An examination of sociocultural factors associated with health and health care seeking among Latina immigrants. J Immigr Minor Health. 2006;8(4):377-85.

39. Cristancho $\mathrm{S}$, et al. Listening to rural Hispanic immigrants in the Midwest: a community-based participatory assessment of major barriers to health care access and use. Qual Health Res. 2008;18(5):633-46.

40. National Academies of Sciences, Engineering, and Medicine: The Integration of Immigrants into American Society. Panel on the integration of immigrants into American society. In: Waters MC, Pineau MG, editors. Committee on population, division of behavioral and social sciences and education. Washington: The National Academies Press; 2015. doi:10.17226/ 21746.

41. Menjívar C. Liminal legality: Salvadoran and Guatemalan immigrants' lives in the United States. Am J Sociol. 2006;111(4):999-1037.

\section{Submit your next manuscript to BioMed Central and we will help you at every step:}

- We accept pre-submission inquiries

- Our selector tool helps you to find the most relevant journal

- We provide round the clock customer support

- Convenient online submission

- Thorough peer review

- Inclusion in PubMed and all major indexing services

- Maximum visibility for your research

Submit your manuscript at www.biomedcentral.com/submit 